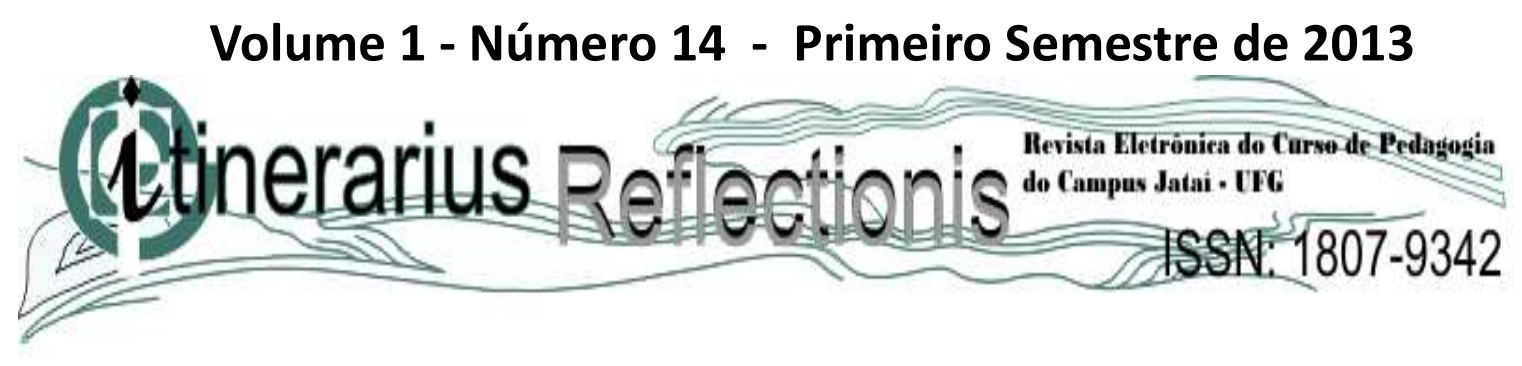

\title{
A AVALIAÇÃO DOCENTE NA PERSPECTIVA DAS POLÍTICAS EDUCACIONAIS
}

\author{
Ivone dos Santos Siqueira \\ Instituto Federal de Educação, Ciência e Tecnologia do Pará - IFPA \\ ivone.siqueiraifpa@gmail.com \\ Sandramara Matias Chaves \\ Professora Adjunta da Universidade Federal de Goiás - UFG \\ sandramara@prograd.ufg.br
}

\begin{abstract}
RESUMO Este artigo discute a avaliação docente destacando a vinculação das políticas avaliativas educacionais com os interesses de mercado segundo a lógica capitalista. Nesse sentido, evidencia-se as contradições presentes na perspectiva de desvelar os viéses ideológicos do processo, como por exemplo, o interesse pelo professor, que camufla a intenção de preparar este profissional para contribuir com o ajuste da educação às exigências do capital. Metodologicamente, este artigo faz uma análise sistêmica da avaliação docente a partir de uma sistemática revisão bibliográfica e de reflexões das autoras. Constatamos que as políticas para os professores estão inseridas num conjunto de reformas mediadas por organismos internacionais, as quais fazem parte do processo de globalização da educação e da redefinição das políticas educativas.
\end{abstract}

Palavras-chave: avaliação docente; política educacional; educação e estrutura econômica.

\section{THE EVALUATION OF TEACHERS IN THE EDUCATIONAL POLITICS PERSPECTIVE}

\begin{abstract}
This article discusses the evaluation of teachers highlighting the link between teacher evaluation policies with the educational interests of the market according to capitalist logic. In this sense, it is clear the contradictions in perspective to reveal the ideological biases of the process, such as the interest by the teacher, which camouflages the intention to prepare professional to help with the adjustment of education to the demands of capital. Methodologically, this article makes a systemic analysis of teacher assessment from a systematic literature review and the authors' reflections. We found that policies for teachers are part of a package of reforms mediated by international organizations, which are part of the process of globalization of education and redefinition of educational policies.
\end{abstract}

Key-words: evaluation of teachers; educational politics; education and economic structure. 


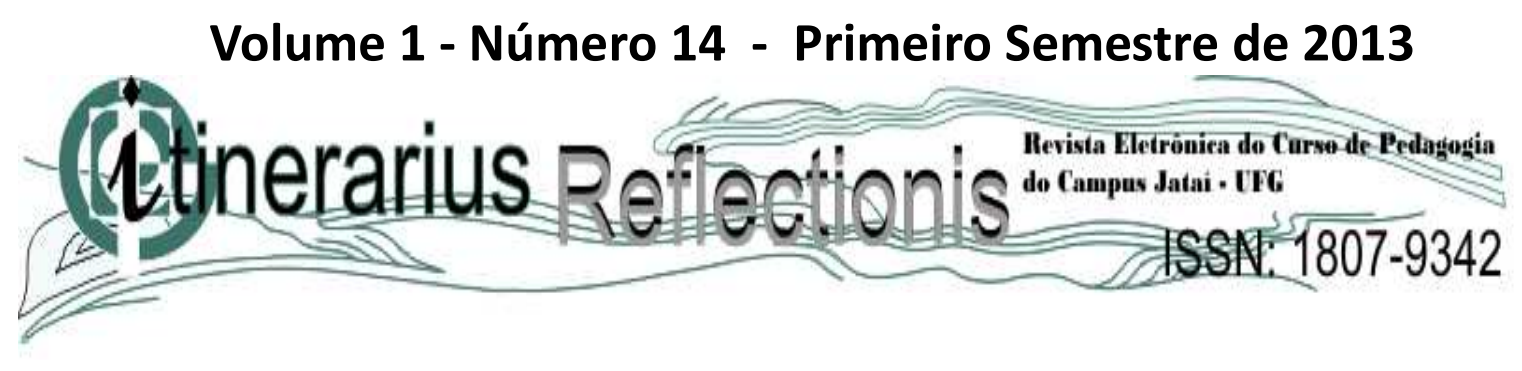

\section{Introdução:}

A avaliação docente tem tido lugar expressivo na agenda de discussões de diversos países, tanto em países centrais quanto periféricos. Isso se deve a fatores de ordem econômica, política e social. As razões de ordem econômica relacionam-se à contenção de recursos para a educação adotada pelos Estados com a redistribuição para outros setores. Dessa forma, tem-se o deslocamento de responsabilidades para o nível local, como meio de responsabilização das escolas, o que contribui para o desenvolvimento de uma cultura avaliativa de prestação de contas. Dentre as razões sociais, inclui-se o crescente interesse por parte de setores da sociedade, com destaque para os órgãos de comunicação que divulgam diariamente notícias sobre os atores da área da educação (SANTOS, 2009).

No Brasil, o controle do Estado sobre a educação fica mais acentuado a partir dos compromissos internacionais assumidos pelo país desde a Conferência de Jomtien em 1990, mais precisamente com o Plano Decenal de Educação para Todos, de 1993, do Governo Collor de Melo (OLIVEIRA, 1995).

Tem sido expressivo o interesse em todo o mundo pela avaliação do professor. De acordo com Torrecilla (2007), a formação de professores e a criação de mecanismos de avaliação de desempenho docente são temas em evidência na agenda educacional de muitos países. O referido autor coordenou um estudo da UNESCO junto a 50 (cinquenta) países. Por meio do número expressivo de países que adotaram a avaliação de desempenho de professores é possível perceber que a avaliação de desempenho se tornou um dos principais temas educacionais da atualidade, entendendo que existem valores agregados sobre o tipo de avaliação proposto.

Este artigo aborda a avaliação docente contextualizado-a no conjunto das políticas educativas e avaliativas. Dessa forma, referenciando a avaliação docente num conjunto de reformas mediadas por organismos internacionais dentro do contexto da globalização da educação e do impacto mundial na redefinição das políticas educativas e seus reflexos nas políticas educacionais brasileiras. 


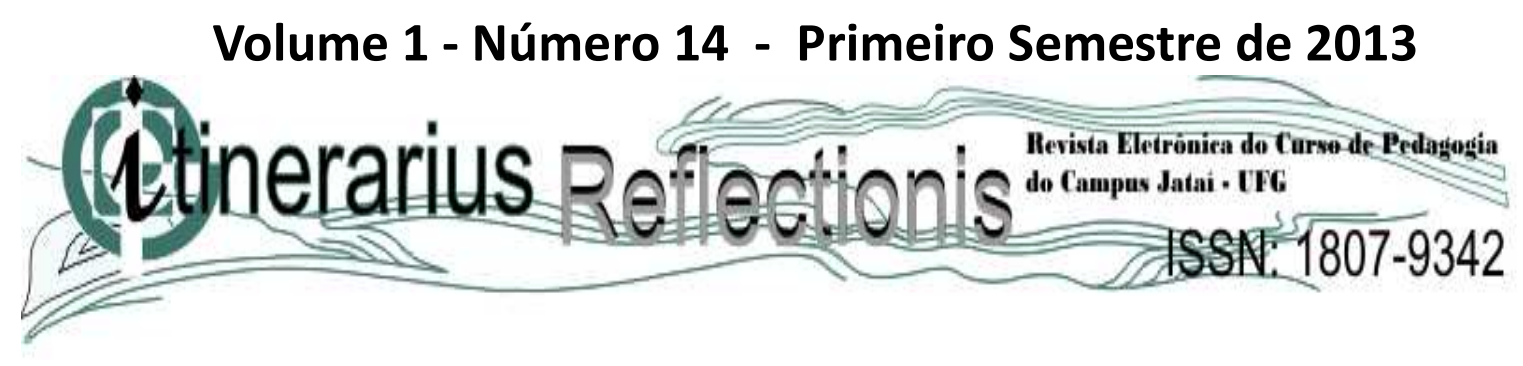

2. As políticas Internacionais e Nacionais para a Educação e a Avaliação Docente

A avaliação docente faz parte de um conjunto de ações que, para serem compreendidas, precisam ser referenciadas em um contexto mais amplo. As políticas educativas e avaliativas estão inseridas num conjunto de reformas mediadas por organismos internacionais. Essas ações fazem parte do processo de globalização da educação e do impacto mundial na redefinição das políticas educativas. O interesse pela avaliação faz parte dos esforços para aliar a educação escolar às necessidades de mercado (AFONSO, 2000).

As políticas avaliativas podem ser melhor compreendidas se forem referenciadas no contexto mundial de forma sistêmica. Os interesses na formulação das políticas educativas, em especial o interesse pela avaliação, está relacionado com a necessidade de mercado, segundo a lógica capitalista.

Segundo estudos de Afonso (2000), com base nos relatórios da OCDE, há três razões essenciais que explicam o interesse dos organismos internacionais pela avaliação, são elas:

\footnotetext{
a) a necessidade que os países têm de dispor de mão-de-obra qualificada; b)à necessidade de, num clima de austeridade orçamental, melhorar a qualidade da educação e da formação para melhor utilização dos recursos; c)à nova partilha de responsabilidades entre as autoridades centrais e locais na gestão das escolas (AFONSO, 2000, p. 64-65).
}

A avaliação foi oficialmente justificada para "o controle da qualidade do sistema educativo". Dessa forma, a lógica do mercado entra nas escolas públicas, promovendo a diminuição dos gastos públicos com a educação e "transferência para as comunidades locais da responsabilidade pela superação dos fracassos educativos". Com isso, o Estado reforçou a sua participação nas avaliações dos resultados escolares (AFONSO, 2000, p. 86).

As avaliações são aplicadas aos estudantes por meio de testes, sendo essa uma das formas de responsabilizar as escolas e os professores pelos resultados. A publicização dos resultados é uma das formas adotadas pelo Estado para responsabilizar a comunidade escolar pelos resultados das avaliações, camuflando o real sistema pragmático da lógica capitalista.

Em relação à transferência de responsabilidades para a comunidade escolar, De Tommasi 


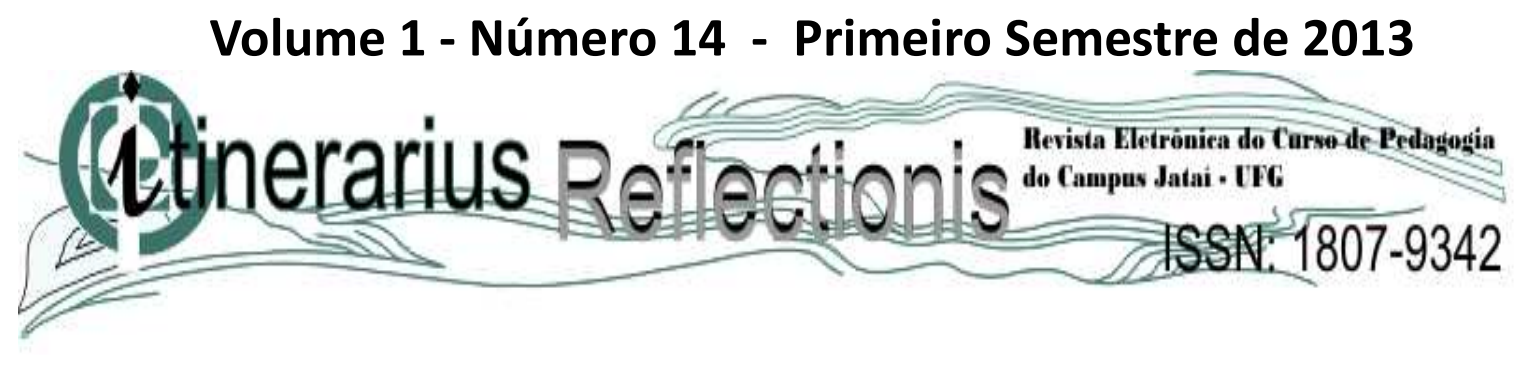

(1997) destaca que tais ações são consequências das reformas contemporâneas da educação em vários países e que se caracterizam pela substituição dos modelos de controle profissional e burocrático tradicionais por mecanismos de quase-mercado e pela transferência do poder decisório para as comunidades escolares.

A divulgação dos resultados educacionais, principalmente dos piores, faz parte das operações dos países centrais, para interferir nas políticas educacionais dos países periféricos, subalternizando-os. Dessa forma, os resultados, ao serem divulgados, trazem consigo a ideia da má gerência, de desperdício de recursos e de falta de produtividade por parte de administradores educacionais e professores. Diante desse quadro, os grupos dominantes trazem a proposta de qualidade, "a qualidade total" (SILVA, 1999). Sobre essa questão o autor esclarece:

\begin{abstract}
As escolas públicas não estão no estado em que estão simplesmente porque gerenciam mal seus recursos ou porque seus métodos ou currículos são inadequados. Elas não têm os recursos que deveriam ter porque a população a que servem está colocada numa posição subordinada em relação às relações dominantes de poder. Seus métodos podem ser inadequados, mas isso não pode ser discutido fora de um contexto de falta total de recurso e de poder. Por isso a questão da qualidade também não pode ser formulada fora desse contexto (SILVA, 1999, p. 20).
\end{abstract}

A transferência de responsabilidades da avaliação para as comunidades locais evidencia mais uma vez a incapacidade do Estado de gerenciar a rede educacional, evidenciando a "periferização" da educação.

Em relação à questão da qualidade, o referido autor destaca que ela já existe na escola privada e que na escola pública ela só existirá se houver reestruturação na distribuição de renda e recursos.

A descrição da situação educacional feita pelos organismos internacionais não deixa margem para discordância porque é um fato, mas é importante ressaltar as intenções neoliberais, explicitadas com a divulgação do diagnóstico dos males que afetam nosso sistema educacional.

Na visão neoliberal, o ponto de referência para condenar a escola atual não são as necessidades da escola e dos grupos envolvidos, sobretudo daqueles que mais sofrem com as desigualdades existentes, mas a necessidade de competitividade e lucro (SILVA, 1999, p. 25). 


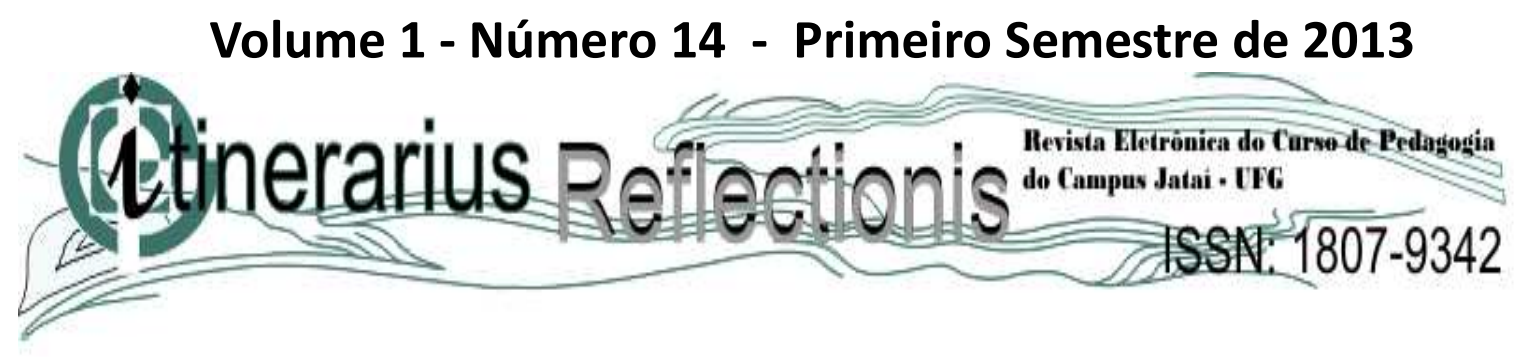

Segundo Coraggio (1998), as políticas educacionais no contexto da globalização são elaboradas para instrumentalizar a política econômica. O autor explica que, na tentativa de se conseguir o crescimento econômico, os organismos internacionais (OCDE, FMI, Banco Mundial e OMC) apostam na redução da pobreza. Tendo em conta a lógica capitalista, a redução da pobreza é praticamente impossível pela forma como o sistema capitalista se mantém.

De acordo com Borges (2003), o Banco Mundial tem sido acusado de adotar uma visão puramente economicista e técnica no processo educativo. Dessa forma, deixa de lado a atividade cotidiana dos estudantes e professores, com o objetivo explícito de formar trabalhadores e reduzir a pobreza, para com isso aumentar o número de consumidores.

Sobre os interesses de mercado para a constituição de amplo mercado consumidor, Lisita (2005) mostra que esses interesses repercutem nas reformas de ensino e na formação de professores, à medida que são estabelecidos currículo e cursos de formação na forma de "pacotes" com a finalidade de formar jovens consumidores numa economia cada vez mais global e digitalizada.

As reformas de ensino e de formação de professores estão nas agendas de modernização das novas instâncias de regulação para os países do capitalismo periférico. Trata-se de soluções e modelos de desenvolvimento social, propostos de forma genérica, tendo a realidade dos países centrais do capitalismo como referência, nos quais a educação é pensada de forma estratégica para viabilizar, a longo prazo, as transformações iniciadas na fase atual de estruturação produtiva (LISITA, 2005, p. 163).

O papel do professor tem uma função muito importante para a concretização dos objetivos das políticas neoliberais. Maués (2003) nos diz que as reformas ditadas pelos países centrais, ao atender a lógica do mercado, podem servir para:

[...] submeter a formação à racionalidade que facilita uma dominação, com a quebra de toda a resistência, por meio da formação de indivíduos que respondam como autômatos às exigências do mercado, mas que não tenham desenvolvido as capacidades críticas que contribuam para buscar a utilização dos conhecimentos como uma forma de emancipação (MAUÉS, 2003, p. 108). 


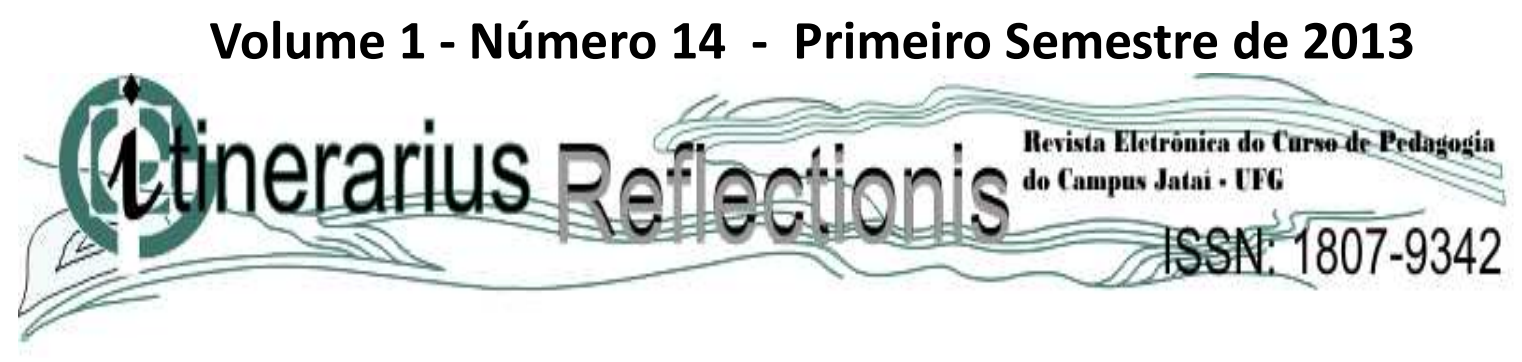

Dentro das reformas, a referida autora destaca a chamada formação do professor a partir do modelo de competências e destaca que a pedagogia das competências serve para alinhar a escola aos interesses do mercado de uma forma direta.

\begin{abstract}
A utilização da pedagogia das competências na formação de professores está ligada às exigências das indústrias e dos organismos multilaterias. Por exemplo, a OCDE, em 2001, durante uma reunião do comitê de educação, enfatizou a necessidade de novas competências para a inovação e para o crescimento. A mesma organização, em 2002, no Simpósio internacional sobre a definição e seleção de competências-chave, ocorrido em Genebra, instituiu um programa internacional de pesquisa denominado Definição e seleção de competências - Deseco -, cuja finalidade é a definição das competências básicas que deverão servir como indicadores para todas as pessoas. Para tanto, o programa deverá desenvolver uma estrutura teórica que permita a identificação das competências apropriadas para fazer face às mudanças, incluindo aí as novas tecnologias. Outro objetivo do programa é o estabelecimento de indicadores internacionalmente comparáveis, que possam validar o alcance das competências-chave estabelecidas (MAUÉS, 2003, p. 106).
\end{abstract}

A formação do professor se tornou uma questão chave para o atendimento dos interesses da lógica capitalista. O professor, ao ter uma formação crítica e dinâmica, contribui para desvendar os viéses ideológicos do processo, o que contraria os interesses do grupo dominante.

Para um trabalho educativo que subsidie os estudantes na percepção das relações de poder, faz-se necessário que a formação de professores siga outras bases. Essas bases incluem uma formação que incorpore a crítica às formas de produção e consumo. Dessa maneira, o professor poderá fomentar o pensamento crítico dos estudantes para que estes não fiquem tão vulneráveis às imposições crescentes da lógica de mercado, as quais encontram nas mídias, com destaque para televisão e internet, condições favoráveis para sua disseminação.

\title{
3. A Avaliação Docente no Brasil
}

Desde a década de 1990, as interferências das agências internacionais têm atuado no sentido de orientar as políticas educacionais brasileiras. As estratégias de ação desses organismos têm estreita relação com as proposições da Conferência Mundial sobre Educação para Todos, realizada em 1990, em Jomtien -Tailândia, o que resultou no documento chamado Declaração Mundial da Conferência de Jomtien. No Brasil, o Plano Decenal de Educação para Todos (1993-2003) foi o 


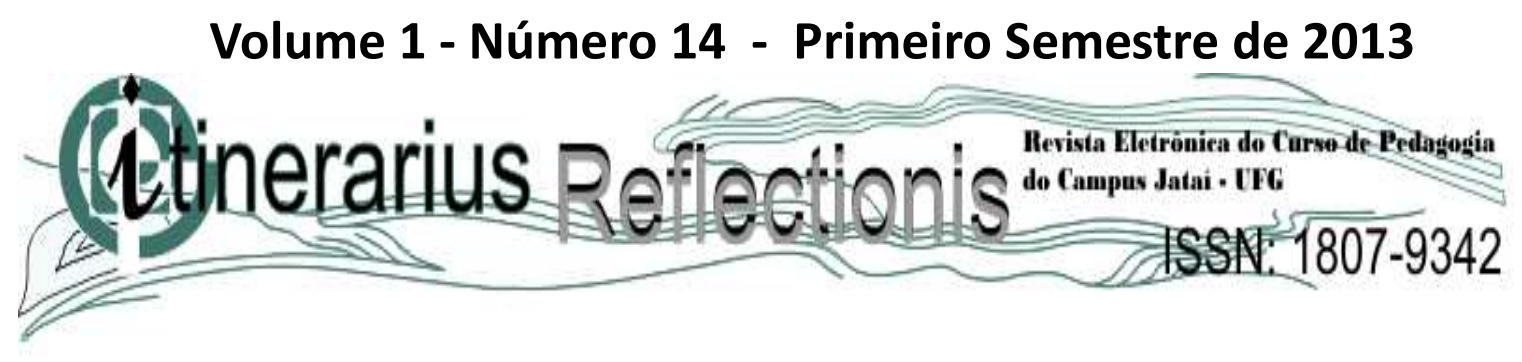

primeiro documento resultante da referida Declaração; na sequência, as idéias emanadas da Declaração de Jomtien estiveram presentes nas políticas e diretrizes educacionais ao longo dos governos de Itamar Franco, Fernando Henrique Cardoso e Luiz Inácio Lula da Silva. Como políticas e diretrizes que trazem as proposições emanadas da Declaração de Jomtien estão: descentralização da gestão, sistema nacional de avaliação, LDB nº 9394/1996, políticas do livro didático, entre outras (LIBÂNEO, 2010).

Vianna (2003) mostra que as avaliações promovidas na década de 90 pelo Governo Federal - SAEB - Sistema de Avaliação do Ensino Básico, ENEM - Exame Nacional do Ensino Médio, e ENC - Exame Nacional de Cursos, são operacionalizações nas políticas públicas brasileiras em decorrência dos acordos firmados a partir da Conferência Mundial sobre Educação para Todos, ocorrida em Jomtien, Tailândia. Vianna destaca que as políticas, a partir dos acordos firmados, centram-se "na aquisição de conhecimentos, no desenvolvimento de habilidades e destrezas, na formação de atitudes, no despertar de interesses e na interiorização de valores" (VIANNA, 2003, p. 43).

A avaliação é parte do processo de gestão da educação e, como tal, o papel das avaliações é justamente levantar informações úteis ao sistema educativo.

\footnotetext{
A questão da avaliação, porém, não é simples. Pelo papel que desempenha no julgamento de valor dos programas e sistemas, a avaliação tem grande poder e, por isso, a importância de uma reflexão aprofundada sobre os diferentes aspectos que a permeiam. Não se pode negar que a avaliação tem força para transformar, justificar ou até desacreditar aquilo que avalia (DEPRESBITERIS, 2001, p. 138).
}

A avaliação em larga escala não consegue identificar se a escola está ou não atendendo suas funções sociais, além de definir a pauta do que vai ser ensinado, uma vez que se estabelece um padrão quando se cobra um conjunto de conhecimentos.

Um ponto para o qual Depresbiteris (2001) chama a atenção é para o significado de qualidade. segundo a autora, a ideia de qualidade não deve ficar limitada à análise dos desempenhos dos estudantes.

O parâmetro para a avaliação dos professores mais utilizado costuma ser a partir de índices 


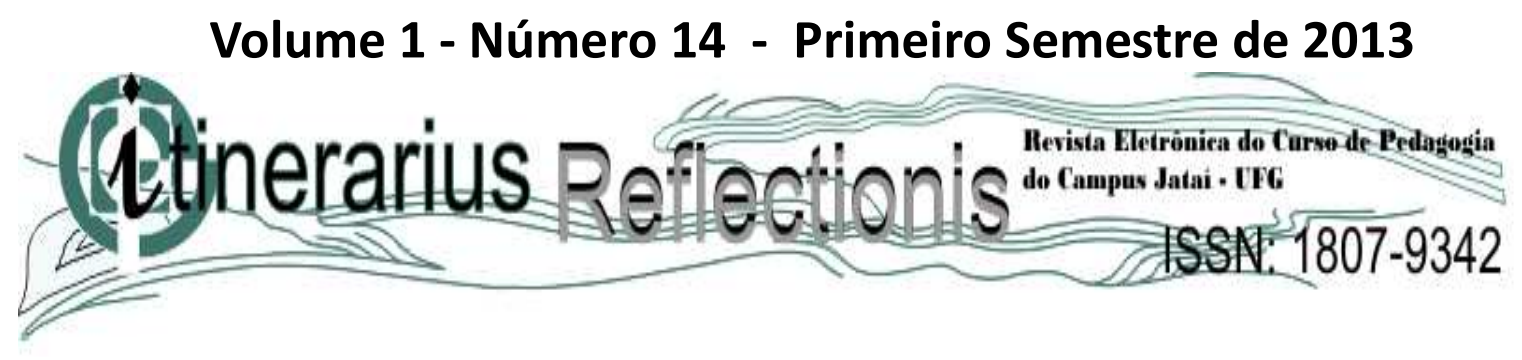

criados para quantificar taxas de aprovação de estudantes. No caso da Educação Básica, o IDEB é o mais utilizado. Esse índice é calculado a partir da aprovação de estudantes nas disciplinas de português e matemática, em que os dados são calculados a partir dos resultados do censo escolar e médias de desempenho nas avaliações do SAEB e na Prova Brasil.

A escola sofre pressão por parte do governo para que assumam as metas do IDEB. As avaliações em larga escala, que deveriam servir para avaliar as políticas educacionais, se configuram como controle verticalizado sobre a escola e seus profissionais.

Em relação ao SAEB, Bauer (2005) chama a atenção para as análises demasiadamente técnicas dos resultados das avaliações dos estudantes e dos questionários aplicados, o que resulta em pouca informação que possa servir de subsídio para uma discussão da prática pedagógica. Tal fato mostra que essas avaliações não são para solução de problemas e sim para manutenção do sistema precário de educação dependente dos países centrais.

Dentre os vários objetivos propostos pelo SAEB, um deles é avaliar a qualidade do ensino e da aprendizagem. Nessa perspectiva, qual seria a ideia de qualidade que subsidia a análise dos resultados? De acordo com Bauer (2005), a idéia que deixa transparecer para o parâmetro de qualidade desejado são "as diretrizes curriculares nacionais com sua formulação amparada na perspectiva dos alunos adquirirem dadas 'competências e habilidades"' (BAUER, 2005, p. 147).

Já a Prova Brasil, criada em 2005, é um complemento da avaliação feita pelo SAEB, “a metodologia da Prova Brasil e do SAEB é a mesma, elas passaram a ser operacionalizadas em conjunto, desde 2007”. A partir do lançamento do Plano de Desenvolvimento da Educação e do Índice de Desenvolvimento da Educação Básica, que estabelecem metas a serem atingidas até 2021, a expectativa é de que nosso país atinja padrões de qualidade comparáveis aos dos países desenvolvidos. Essas medidas mostram a consolidação das avaliações nacionais e apontam a valorização do uso dos resultados como no monitoramento das políticas educacionais (CASTRO, 2009, p. 282).

Em relação ao ENEM, que é um exame que avalia o desempenho individual do aluno ao término do Ensino Médio e tem caráter voluntário, observa-se que a adesão dos estudantes ao mesmo se deve principalmente, à utilização das notas em processos seletivos de acesso ao ensino 


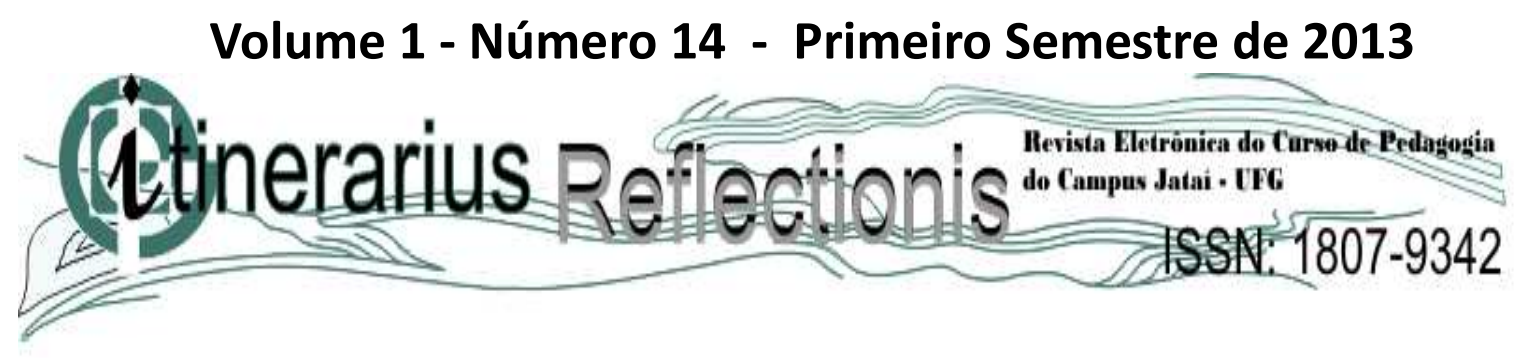

superior em diversas Instituições (CASTRO, 2009). Isso demonstra pragmaticamente a lógica capitalista de universitarização/profisssionalização.

Em articulação com os diversos sistemas de avaliações nacionais, surge o desenvolvimento de sistemas regionais ou locais de avaliação. Os sistemas regionais ou locais apresentam vantagens por coletar informações diretamente das escolas, permitindo uma investigação sobre as especificidades locais, o que não acontece nas avaliações nacionais (CASTRO, 2009).

A consolidação das políticas nacionais de avaliação impulsionam o crescimento das avaliações a nível local:

Paralelamente aos sistemas nacionais, vários estados e municípios também organizaram sistemas locais e regionais de avaliação das aprendizagens. Todas essas iniciativas indicam a progressiva institucionalização da avaliação como mecanismo importante para subsidiar o processo de formulação e monitoramento de Políticas Públicas responsáveis e transparentes que devem nortear o aprimoramento de ações de melhoria da aprendizagem. Mais do que isso, a consolidação da política de avaliação educacional no Brasil é hoje instrumento fundamental do processo de prestação de contas à sociedade e de enriquecimento do debate público sobre os desafios da educação no país (CASTRO, 2009, p. 273).

Esses sistemas regionais ou locais, de alguma forma ressignificam a lógica da avaliação porque estão mais próximos das escolas e traçam suas próprias metas.

De acordo com Castro (2009, p.287), "cerca de onze estados brasileiros e duas capitais já possuem sistemas próprios para avaliar as suas Redes de Ensino, produzindo resultados por escola". Em alguns Estados, além da avaliação em larga escala, também foi adotada a avaliação institucional; a título de exemplo, podemos citar Minas Gerais, Ceará, Bahia e Goiás.

Em Minas Gerais, a avaliação dos professores da Rede Estadual de Ensino foi institucionalizada em 2003 pela chamada Avaliação de Desempenho Individual (ADI). Os professores são avaliados em quatro critérios: desenvolvimento profissional, relacionamento interpessoal, compromisso profissional e interpessoal e habilidade técnica e profissional. Os professores são avaliados por uma comissão de avaliação composta pelo diretor, dois membros eleitos pelos professores e mais dois membros indicados pelo diretor. A ADI é feita a partir do preenchimento do formulário de condições de trabalho, preenchimento do Plano de Gestão do 


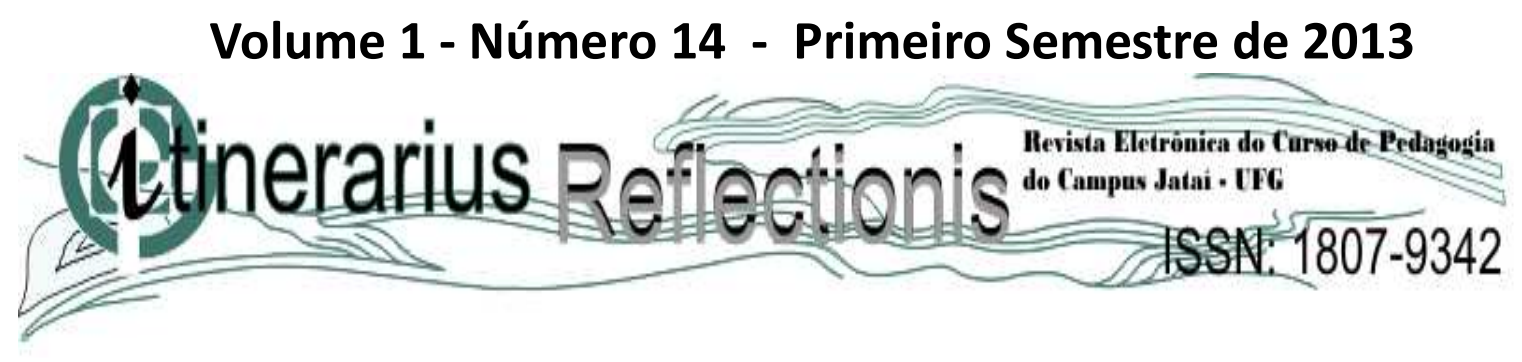

Desempenho Individual e de entrevistas realizadas pela comissão. Segundo Alves (2006, p.3) "a avaliação de desempenho individual (ADI) figura como elemento estratégico no quadro de ações a serem implantados no Estado em direção a tal reestruturação administrativa". A autora relata que a ADI possui mecanismos de premiação e punição, como o modelo de gestão de recursos, tendo por base a produtividade e, explicitando, assim, a lógica de mercado.

O Estado do Ceará conta com o Sistema Permanente de Avaliação da Educação Básica do Ceará (SPAECE), o qual compreende: Avaliação de Desempenho Acadêmico, Avaliação Institucional e Estudos e Pesquisas Educacionais. Para Lima (2007, p. 143), os objetivos do SPAECE são: "promover a avaliação do desempenho dos alunos, reconhecer escolas com melhores resultados e premiar professores, funcionários e alunos destas escolas como forma de incentivo e valorização".

$\mathrm{Na}$ Bahia, os professores da Rede Estadual de Ensino passam por avaliações discursivas e objetivas, que avalia todos os professores da Rede Estadual. Segundo informações da Seduc/BA, os professores que são classificados no exame recebem quinze por cento (15\%) de aumento salarial e a avaliação de desempenho é utilizada também para a geração de "subsídios para a construção de políticas públicas para melhoria da qualidade da educação no Estado". A avaliação de desempenho é direcionada aos professores ativos, coordenadores pedagógicos, diretores e vice-diretores. O processo avaliativo é feito em duas etapas, sendo a primeira com questões objetivas e discursivas; já a segunda, consta de uma avaliação institucional que considera também o censo com o rendimento escolar dos estudantes.

No Estado de Goiás, os professores da Rede Estadual de Ensino são avaliados por comissão de avaliação instituída no local onde o servidor é lotado. Na avaliação do desempenho dos professores, são utilizados três instrumentos para o registro individual de informações de cada professor: questionário de avaliação do servidor pela comissão de avaliação; questionário de autoavaliação e Portfólio (GOIÁS, 2009).

O desenvolvimento dos sistemas de avaliações regionais e locais faz parte de um conjunto de reformas que remete à escola a responsabilização pelas mais diversas tarefas. Essas ações fazem parte das chamadas políticas de descentralização. 


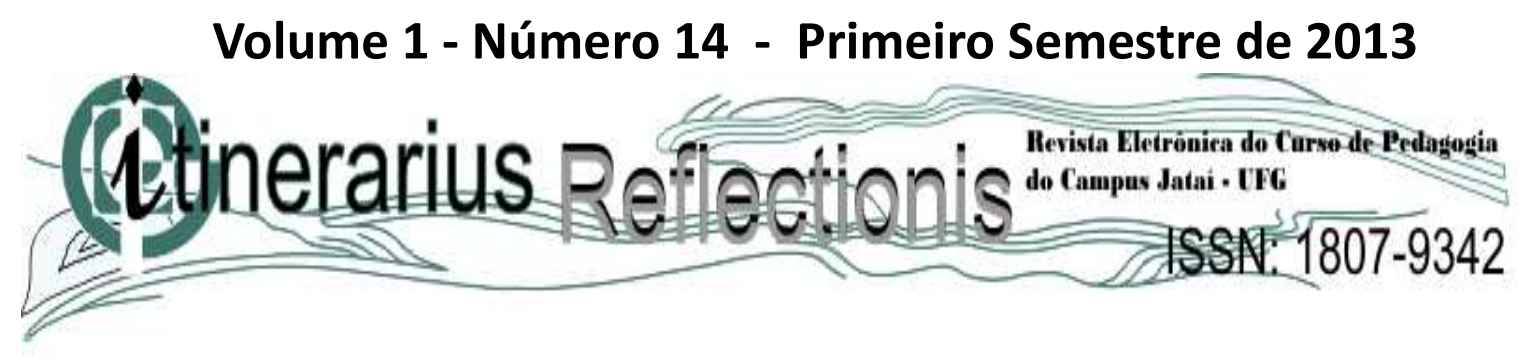

Segundo Souza (2003, p. 21) "a descentralização é a principal ferramenta apresentada pelo Banco Mundial para a implantação das reformas educacionais que ele julga necessárias”. De acordo com o referido autor, a política de descentralização foi o principal instrumento utilizado nas reformas educacionais contemporâneas, com destaque para a América Latina. A descentralização é apresentada pelos organismos internacionais como uma "solução" para resolver os problemas do ensino.

De Tommasi (1997) aponta algumas ações consideradas pelo Banco Mundial como sendo prioritárias para o Brasil, no sentido de "resolver" os problemas educacionais, sendo que a baixa qualidade era naquele momento considerada a causa de todos os males. Dentre as ações podemos ressaltar: a) fornecimento de livros didáticos; b) melhoria do ensino em sala de aula, por meio de capacitação dos professores em serviço, da instrução à distância e de materiais didáticos programados; c) fortalecimento da administração do sistema educativo, por meio de: "reestruturação orgânica", "fortalecimento dos sistemas de informação" e "aumento de atitudes administrativas, por meio do aumento das oportunidades profissionais, de uma definição clara do plano de carreira e do estabelecimento de sistemas de avaliação de desempenho" (DE TOMMASI, 1997, p. 199-200).

Dentre as recomendações do Banco Mundial para a educação brasileira, De Tommasi (1997) destaca a autonomia escolar com a descentralização de funções administrativas para as escolas. Dessa forma "cada escola prepara seu plano de desenvolvimento, visando a melhoria do desempenho no que diz respeito à gestão, qualidade da infra-estrutura e produtividade" (DE TOMMASI, 1997, p. 208).

Segundo Abu-Duhou (2002), o movimento de descentralização iniciou-se no Leste Europeu e em parte dos Estados Unidos. A descentralização do controle da gestão das escolas e dos sistemas educativos teve como fator motivador o crescimento econômico:

[...] A descentralização do controle da gestão das escolas e dos sistemas foi imposta, de fora para dentro, por dirigentes políticos que procuravam melhorar a produtividade e o crescimento econômico do setor da educação. Os fatores econômicos determinaram a natureza de reestruturação, já que os governos nacionais estabeleceriam uma ligação entre o desenvolvimento da sua economia e o grau de instrução da população ativa (ABUDUHOU, 2002, p. 25). 


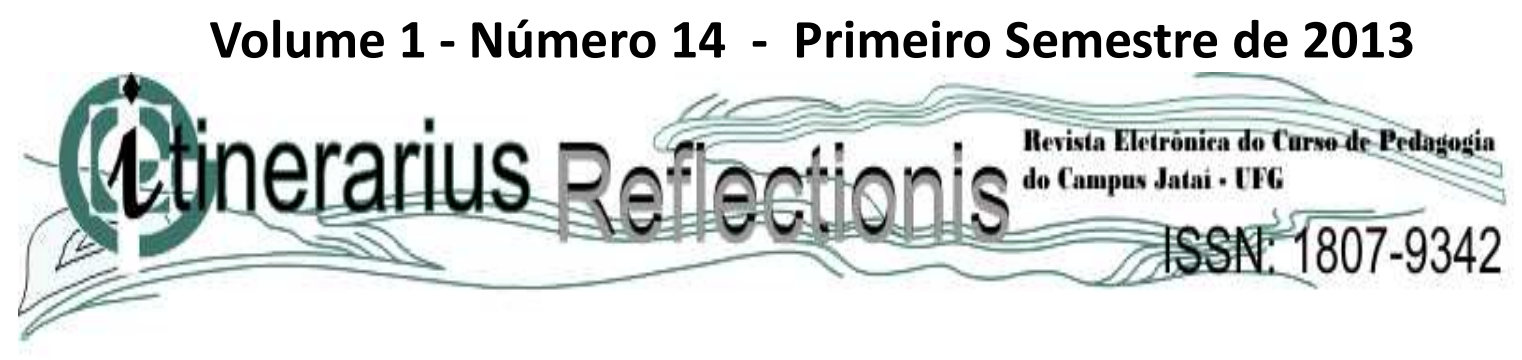

A descentralização consiste numa ferramenta de gestão pela qual o Estado delega uma autoridade relativa ao nível local. Com isso, há a transferência de recursos diretamente para a escola; em contrapartida, a avaliação das ações da escola permanece no âmbito da autoridade central (ABU-DUHON, 2002).

As discussões sobre descentralização e avaliação sempre trazem consigo a "qualidade da educação" como objetivo prioritário. Segundo Enguita (1999), a palavra qualidade se converteu em meta compartilhada, desde as declarações dos organismos internacionais até as conversas de bar. Segundo o autor, até aqueles que se sentem desconfortáveis com o termo não conseguem se livrar dele e com frequência fazem uso do termo qualidade para coroar suas propostas.

A questão da qualidade da educação está presente quando se discute a avaliação de professores. Tendo em vista que a avaliação de professores no nosso país tem como parâmetro as avaliações dos estudantes, estes também estão permeados pelo ideal de qualidade que trazem em si "as competências e habilidades".

Sobre essa discussão do parâmetro de qualidade que permeia as avaliações na educação básica, Depresbiteris (2001) diz que a estimativa de qualidade é complexa e carregada de valores. A autora sugere que "antes de qualquer decisão sobre a avaliação da qualidade da educação, deve ocorrer uma análise do contexto em que o processo educacional se desenvolve" (DEPRESBITERIS, 2001, p. 139).

Segundo Santos (2009, p. 14) é necessário deixar claro os conceitos de competência, desempenho e eficácia quando se coloca o professor como sujeito avaliado. Para o autor, competência está relacionada com o conjunto de conhecimentos específicos dos professores, sobre o que eles sabem e fazem; já o conceito de desempenho se refere ao comportamento no trabalho, dependendo da competência, do contexto em que trabalha, da capacidade de mobilização e aplicação das competências, associado ao ato de ensinar e aos efeitos sobre o aluno; por sua vez, a eficácia se refere ao efeito do desempenho do professor sobre o aluno, incluindo as aprendizagens.

A discussão sobre qualidade é abordado por Freitas (2005, p. 920) considerando o seu caráter negociável. O autor diz que: 


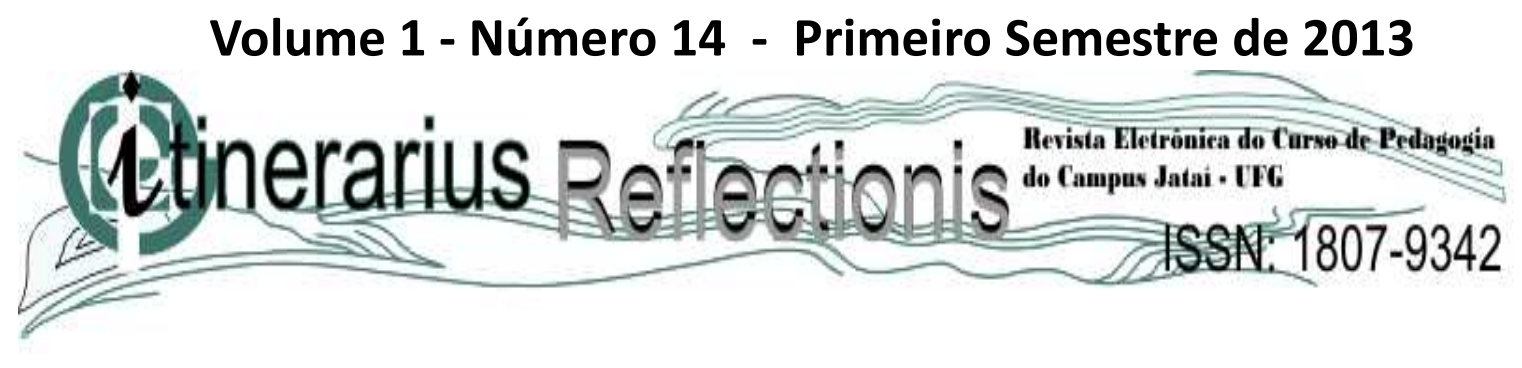

a qualidade negociável é um conceito que nos chega por intermédio de um estudo de Anna Bondioli (2004) [...] para a autora, definir qualidade implica explicitar os descritores fundamentais de sua natureza, ou seja: seu caráter negociável, participativo, autoreflexivo/plural, processual e transformador (FREITAS, 2005, p. 920-921).

Nessa perspectiva, a qualidade tem caráter de significação compartilhada e de "produção coletiva, onde cada membro do grupo contribui de acordo com seu próprio nível de responsabilidade". A qualidade negociável é implementada através da avaliação institucional. "São os atores sociais envolvidos com os problemas os que detêm conhecimentos importantes sobre a natureza desses problemas, seus limites e possibilidades" (FREITAS, 2005, p. 923).

A qualidade negociável implica em práticas de natureza participativa. Tendo em vista que a escola é um universo complexo, o diálogo se constitui como meio de se chegar a um acordo entre os envolvidos. Dessa forma, a qualidade negociável traz o exercício da participação.

Vianna (2003) mostra que os resultados das avaliações dos estudantes incidem sobre a avaliação dos professores. $\mathrm{O}$ autor destaca as consequências em decorrência dessas ações:

\footnotetext{
A avaliação - sempre considerando o caso brasileiro - procura, igualmente, estabelecer a eficiência dos sistemas, avaliando, indiretamente, o êxito da ação dos professores. Avaliar professores, direta ou indiretamente, é sempre um processo que demanda grande sensibilidade, pois gera múltiplas reações com ressonâncias negativas, qualquer que seja o contexto. A avaliação do professor, por sua vez, é vista com certa suspeita, pois, na concepção dos avaliados, e às vezes com justa razão, pode significar, em muitos casos, transferência de escola ou de cidade, redução salarial, diminuição do número de aulas, concessão de bônus para os supostamente melhores e, ainda, numa situação extrema, demissão. Tudo isso integra a mitologia educacional, bastante fértil em imaginar situações as mais diversas (VIANNA, 2003, p. 46).
}

Segundo Vianna (2003, p. 47) “o ato de avaliar implica, necessariamente, considerar múltiplas variáveis, inclusive sociais, econômicas e culturais, que podem invalidar as ações subseqüentes ao trabalho de avaliação". Logo, o baixo desempenho dos estudantes não está relacionado somente ao professor, sendo que este, muitas das vezes não tem condições de atuar na eliminação das múltiplas variáveis que incidem sobre os resultados.

As ações dos professores são julgadas cada vez mais com base no desempenho 


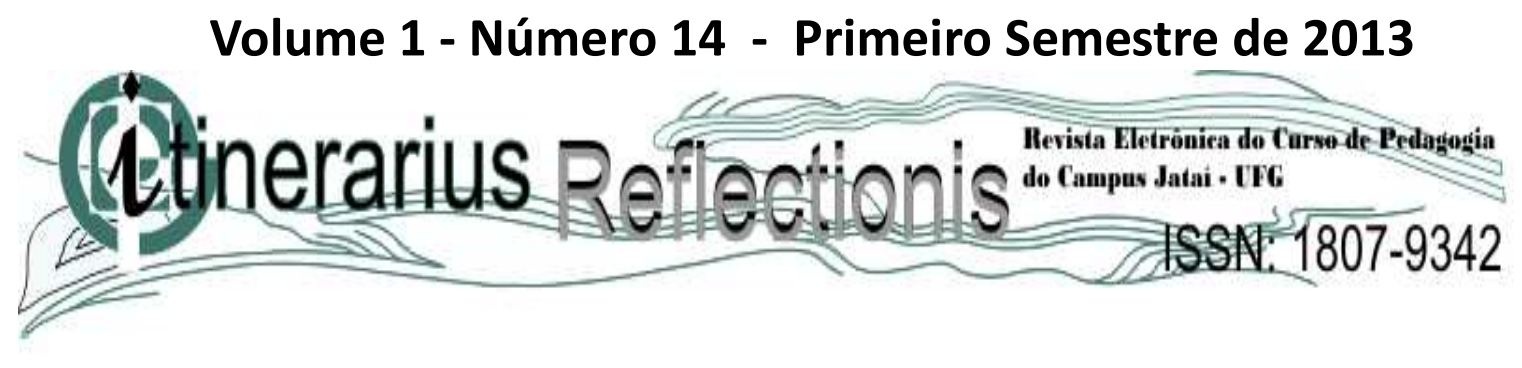

organizacional a partir de resultados mensuráveis. As pressões sobre os professores, formalizadas pelas avaliações com criação de bancos de dados, é uma forma de regulação institucional (BALL, 2005).

No âmbito legal, a avaliação docente está prevista na Lei de Diretrizes e Bases da Educação Nacional, Lei 9.394/96, em seu art. 67, caput e inciso IV, que dispõe:

Art. 67. Os sistemas de ensino promoverão a valorização dos profissionais da educação, assegurando-lhes, inclusive nos termos dos estatutos e dos planos de carreira do magistério público: [...] IV - progressão funcional baseada na titulação ou habilitação, e na avaliação do desempenho (BRASIL, 1996).

Até 1998, os servidores públicos não tinham preocupação em relação à avaliação de desempenho, após o estágio probatório. Nesse período, com a publicação da Emenda Constitucional $\mathrm{n}^{\text {o }} 19$ de 04 de junho, a avaliação de desempenho passou a ter destaque na vida funcional dos servidores públicos. A atual Constituição Federal prevê no artigo 37 a associação entre o princípio da eficiência na administração pública. O artigo 37 institui a participação do usuário na administração pública e regula a prestação de serviços públicos assegurando a manutenção de serviços ao usuário e a avaliação periódica da qualidade dos serviços (BRASIL, 1988).

Em 2009, o Conselho Nacional de Educação/Câmara da Educação Básica aprovou o Parecer CNE/CEB No 9/2009, que estabelece as Diretrizes para os Novos Planos de Carreira e de Remuneração para o Magistério dos Estados, do Distrito Federal e dos Municípios; a partir desse documento a avaliação de desempenho dos professores se insere nas Diretrizes:

Um assunto de relevo que recai sobre as Diretrizes para a carreira refere-se à avaliação de desempenho. Embora pouco executada pelos sistemas de ensino, crescem as proposições sobre certificação de professores e sobre as concepções avaliativas. De um lado, há os que defendem os critérios formulados pela EC n $n^{\circ}$ 19/98. De outro, os que creem numa melhor eficácia da avaliação a partir de elementos que considerem o trabalho coletivo, as condições objetivas do trabalho individual, a interação com os critérios de formação continuada, a participação dos profissionais na elaboração e execução do projeto pedagógico da escola, conforme estabelece a LDB, dentre outras variáveis. Da mesma forma carecem de instruções sobre a aplicação dos resultados de tais avaliações e como estes devem ser utilizados para determinar a remuneração dos integrantes do magistério (BRASIL, 2009, p. 


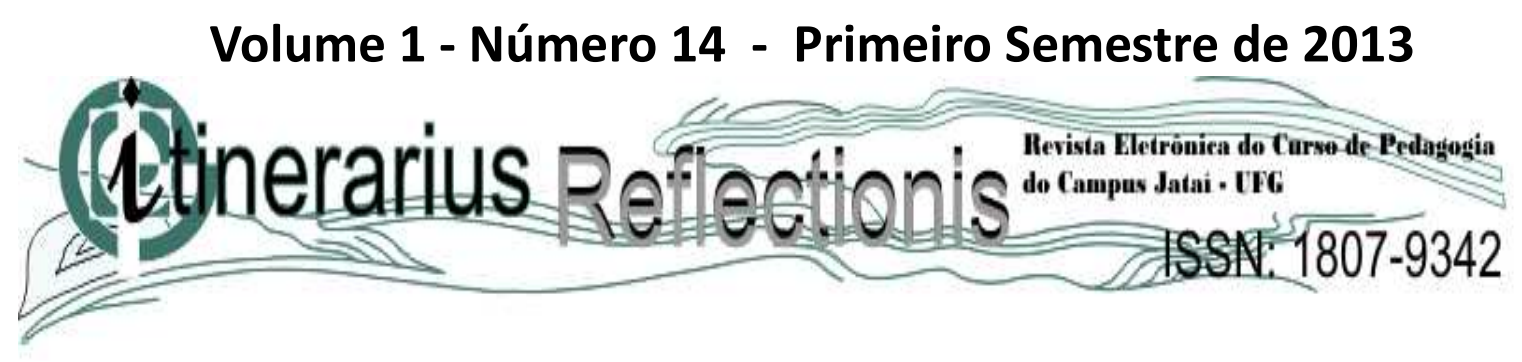

23).

Segundo Dourado (2009), durante muito tempo uma parcela dos trabalhadores da educação se recusou a debater a importância da avaliação docente. $\mathrm{O}$ autor ressalta que, por muitas vezes, foram feitas tentativas de se discutir a articulação entre avaliação de desempenho e avaliação institucional, em busca de algo mais abrangente do que os testes estandartizados. Nessa perspectiva, o autor ressalta que:

\footnotetext{
Nós avaliamos na escola, os pais avaliam, os estudantes avaliam, os professores, a coordenação, os diretores; mas, em que pese tudo isso, a avaliação é um dos temas menos discutidos da prática educativa. Precisamos avançar nesse debate, trabalhando, inclusive, os seus limites e possibilidades, para lhe definir um norte, uma vez que os planos nacionais, inevitavelmente, terão que debruçar sobre ela - e as próprias diretrizes já apontam nessa direção (DOURADO, 2009, p. 137).
}

É recente a discussão sobre avaliação docente nas políticas públicas brasileiras. O Ministério da Educação (MEC) anunciou por meio da portaria normativa $\mathrm{n}^{\circ} 14$, de 21 de maio de 2010, o Exame Nacional de Ingresso na Carreira Docente. Através da portaria o MEC delega ao INEP a responsabilidade pela avaliação que "constitui-se de uma avaliação de conhecimentos, competências e habilidades para subsidiar a contratação de docentes para a educação básica no âmbito dos Estados, do Distrito Federal e dos Municípios" (BRASIL, 2010).

O Exame Nacional de Ingresso na Carreira Docente, segundo a referida portaria, tem o objetivo de "subsidiar os Estados, o Distrito Federal e os Municípios na realização de concursos públicos para a contratação de docentes para a educação básica”. (BRASIL, 2010).

A avaliação docente começa a ser discutida no âmbito das políticas educacionais. Nos próximos anos essa discussão deverá ganhar maior destaque no cenário brasileiro, haja vista as sinalizações nesse sentido.

\section{Considerações Finais}




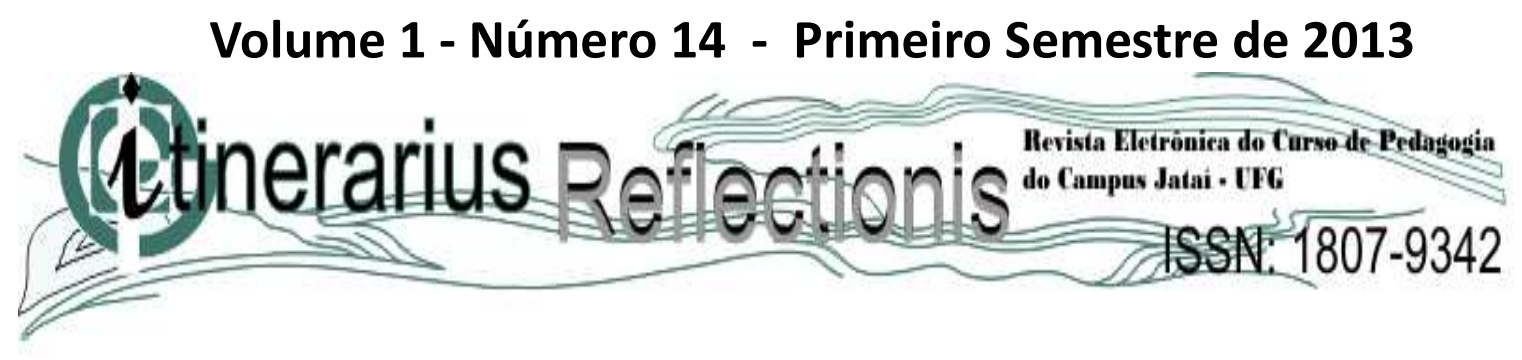

A definição de políticas para os professores no Brasil insere-se como parte das políticas educacionais orientadas pelos organismos internacionais, onde os mesmos recomendam que os estabelecimentos educacionais sejam avaliados por seus resultados. Na tentativa de atender às recomendações exigidas nesse processo avaliativo, a escola e, principalmente, o professor são pressionados a adaptar-se às novas demandas. Isso tem implicações nas mudanças de currículo e nas estratégias de ensino.

Percebe-se que as políticas de avaliação docente brasileiras encontram-se desarticuladas de um projeto pedagógico mais amplo, que viabilize programas de formação ou discussão das condições de trabalho dos professores.

A avaliação do docente inclui variáveis internas e externas no contexto da avaliação educacional. Isso significa que a avaliação docente não pode ser feita isoladamente porque as relações são bem mais complexas do que aparentam. Numa dimensão mais aprofundada, é importante mostrar as relações entre a educação e estrutura econômica.

As políticas educacionais para a avaliação de professores trazem em si ideias e valores dos grupos dominantes com a intenção de fazer estudantes e professores aderirem aos interesses desses grupos. Nessa questão, o papel do professor é essencial e isso justifica o grande interesse por esse profissional, a "preocupação" com o professor que traz às ocultas o interesse de preparar o professor para contribuir com o ajuste da educação às exigências do capital.

\section{Referências Biblioráficas}

ABU-DUHON, Ibtisam. Uma Gestão mais autônoma das escolas. Brasília: UNESCO, IIEP, 2002.

AFONSO, Almerindo Janela. Avaliação Educacional: regulação e emancipação. São Paulo: Cortez, 2000.

ALVES, Ana Carolina Timo. As Reformas em Minas Gerais: Choque de Gestão, Avaliação de Desempenho e Alterações no Trabalho Docente. In: VI Seminário da REDESTRADO - Regulação Educacional e Trabalho Docente. Rio de Janeiro, nov. 2006.

BALL, Stephen. Profissionalismo, gerencialismo e performatividade. Caderno de Pesquisa, São Paulo, v.35, n.126, set./dez. 2005. 


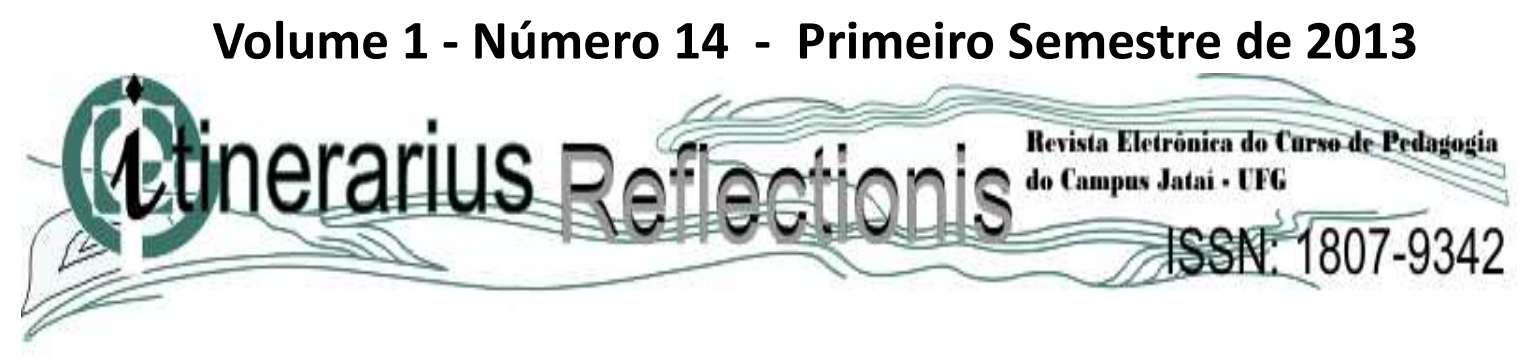

BAUER, Adriana. Saeb e qualidade de Ensino: algumas questões. Estudos em Avaliação Educacional, v. 16, n. 142 31, jan./jun. 2005.

BORGES, André. Governança e política educacional: a agenda recente do Banco Mundial. Revista Brasileira de Ciências Sociais. v.18, No 52, 2003.

BRASIL. Lei 9394 - LDB - Lei das Diretrizes e Bases da Educação, de 20 de dezembro de 1996.

BRASIL. Constituição Federal. Constituição da República Federativa do Brasil. Brasília: Senado, 1988.

BRASIL. Parecer CNE/CEB no 9/2009. Estabelece diretrizes para os novos planos de carreira e remuneração para o magistério dos Estados, do Distrito Federal e dos Municípios. Cadernos de Educação. Brasília, n. 21, nov. 2009.

BRASIL. Portaria Normativa $\mathbf{n}^{\mathbf{0}}$ 14, de 21 de maio de 2010. Diário Oficial da União: seção 1, p. 11. Maio. Brasília, 2010.

CASTRO, Maria Helena Guimarães de. A Consolidação da Política de Avaliação da Educação Básica no Brasil. Meta: Avaliação. Rio de Janeiro, v. 1, n. 3, p.271-296, set./ dez. 2009.

CORAGGIO, José Luis. Propostas do Banco Mundial para a educação: sentido oculto ou problemas de concepção. In: TOMASSI, Lívia de. Et al. (Org.). O Banco Mundial e as políticas educacionais. São Paulo: Cortez, 1998.

DEPRESBITERIS, Lea. A avaliação na educação básica: ampliando a discussão. Estudos em Avaliação Educacional. Fundação Carlos Chagas, n. 24 jul./dez. 2001.

TOMMASI, Livia de; WARDE, Miriam Jorge; HADDAD, Sergio. O Banco Mundial e as políticas educacionais. São Paulo: Cortez, 1998.

DOURADO, Luiz Fernando. Uma política de educação para a carreira na educação básica. Cadernos de Educação. Brasília, n. 21, p. 132-144, nov. 2009.

ENGUITA, Mariano Fernández. O discurso da qualidade e a qualidade do discurso. In: GENTILI, Pablo ${ }^{a}$ A. \& SILVA, Tomaz Tadeu da. Neoliberalismo, qualidade total e educação - Visões críticas. 8 a .ed., Petrópolis: Vozes, 1999.

FREITAS, Luiz Carlos. Qualidade negociada: avaliação e contra-regulação na escola pública. Educação \& Sociedade, Campinas, v.26, n.92, p. 911-933, out. 2005. 


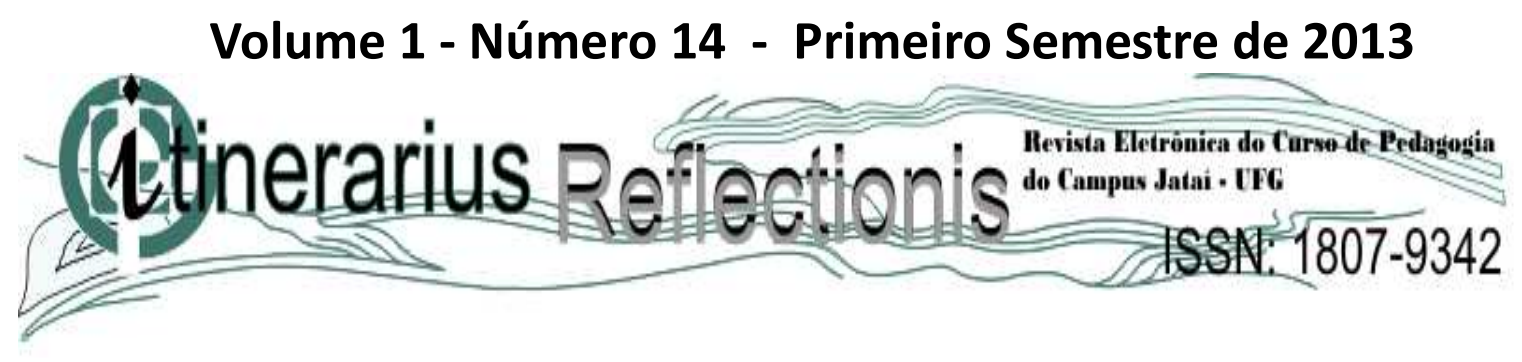

GOIÁS. Secretaria do Estado da Educação. Manual de orientação para a avaliação de desempenho dos servidores da Seduc/GO. Goiânia, 2009.

LIBÂNEO, José Carlos. A escola brasileira em face de um dualismo perverso: escola do conhecimento para os ricos, escola do acolhimento social para os pobres. Palestra apresentada no X Encontro de Pesquisa em Educação da Anped-Centro Oeste, realizado na Universidade Federal de Uberlândia, 2010.

LIMA. Alécio Costa. O Sistema permanente de avaliação da Educação Básica no Ceará (SPAECE) como expressão da política pública de avaliação educacional do Estado. Dissertação de Mestrado. Ceará: UECE, 2007.

LISITA. Verbena Moreira Soares de Sousa. Reformas educacionais e formação de professores no contexto da reestruturação produtiva. In: FRANCO, M. A. S. (org.). O lugar do professor na pesquisa educacional. Santos, São Paulo: Editora Universitária Leopoldinaum, 2005.

MAUÉS, Olgaíses Cabral. Reformas internacionais da educação e formação de professores. Cadernos de Pesquisa. Fundação Carlos Chagas, São Paulo, no.118, mar. 2003.

OLIVEIRA, Romualdo Portela de. Política Educacional: impasses e alternativas. São Paulo: Cortez, 1995.

SANTOS, Alvaro Almeida dos. Avaliação de Professores em Portugal - Modelos e Perspectivas. In: RUIVO, João; TRIGUEIROS, António. Avaliação de Desempenho de Professores. RVJ, Editores, 2009.

SILVA, Tomaz Tadeu da. A "nova" direita e as transformações na pedagogia da política e na política da pedagogia. In: GENTILI, P.\& SILVA, Tomaz Tadeu da. Neoliberalismo, Qualidade Total e Educação. Petrópolis: Vozes, 1999.

SOUZA, Ângelo Ricardo de. As relações entre os resultados da avaliação e os modelos de gestão escolar. Educar, n. 22, p. 17-49, 2003.

TORRECILLA, Javier Murillo. Avaliação de Desempenho e carreira docente: um estudo em cinquenta países da América e Europa. In: BALZANO, Sônia (Org.). O Desafio da Profissionalização Docente no Brasil e na América Latina. Brasília: CONSED, UNESCO, 2007.

VIANNA, Heraldo Marelim. Avaliações Nacionais em Larga Escala: análises e propostas. Estudos em Avaliação Educacional, n. 27, jan./jun. 2003. 